\title{
Regional analysis of climate and bioclimate change in South Italy
}

\author{
A. Capra, P. Porto \& B. Scicolone \\ Department of Agro-forestry and Environmental Sciences and \\ Technologies, Mediterranean University of Reggio Calabria, Italy
}

\begin{abstract}
In this paper, monthly values of rainfall $(P)$ and temperature $(T)$ recorded in Southern Italy (Calabria and Sicily) during the period 1921-2000 are investigated. In particular, a series of 211 raingauge and 53 temperature stations are analysed for evidence of trend by using the linear regression and the Kendall non-parametric test. The tests are applied at a seasonal and annual scale; a spatial analysis is also carried out at both a regional and sub-regional scale in order to check the effect of different sub-areas on these trends. An additional investigation useful for checking the climate change effects on vegetation is also included analysing bioclimatic parameters such as evapotranspiration and aridity index. The results obtained confirmed, for the two investigated regions, the importance of the climatic analysis carried out at a regional scale. In fact, the tests showed for both the $P$ and $T$ records a strong difference between the two investigated regions. In particular, the total annual $P$ showed a decreasing and increasing trend with -344 and $197 \mathrm{~mm} / 100$ years respectively in the Tyrrhenian and Ionian sub-regions of Calabria and a decreasing trend with $-179 \mathrm{~mm} / 100$ years in Sicily. A decreasing trend is evident in the Tyrrhenian sub-region for the mean annual values of $T_{\max }\left(-3.2^{\circ} \mathrm{C} / 100\right.$ years $)$ and $T_{\min }\left(-2.9^{\circ} \mathrm{C} / 100\right.$ years $)$; a different trend is shown in the Ionian sub-region where the mean annual values of $T$ showed an increase of 2.2 and $0.9{ }^{\circ} \mathrm{C} / 100$ years for $T_{\max }$ and $T_{\min }$ respectively. In contrast, a clear increasing trend $\left(1.8\right.$ and $2.2{ }^{\circ} \mathrm{C} / 100$ years $)$ is shown for both $T_{\max }$ and $T_{\min }$ in Sicily. A detailed analysis involving the calculation of 10-year moving averages, showed a significant change of trending after the 1950s for $P$ and after 1970s for $T$.

Keywords: climate change, precipitation, temperatures, bioclimatic parameters.
\end{abstract}




\section{Introduction}

It has been observed that during the last 100-150 years the Italian climate has changed and it has resulted in a rise of temperature and aridity. According to Brunetti et al. [1], during the period 1865-2000, the mean annual temperature $\left(T_{y a}\right)$ indicates a $0.4^{\circ} \mathrm{C} / 100$ years rise within the northern areas $(\mathrm{N})$ of the country (continental zone) and a $0.7^{\circ} \mathrm{C} / 100$ years rise in the central (C) and southern (S) Italy (peninsular zones). More particularly, at seasonal scale, the slopes of the regression line are greater during the winter season, ranging from $0.7^{\circ} \mathrm{C} / 100$ years $(\mathrm{N})$ to $0.9^{\circ} \mathrm{C} / 100$ years $(\mathrm{S})$, while for the summer season they are lower and in some cases not significant. A negative trend of the annual rainfall $\left(P_{y}\right)$ is evident within both $\mathrm{N}$ and $\mathrm{S}$ areas with a slope equal to $-47 \mathrm{~mm} / 100$ years and $104 \mathrm{~mm} / 100$ years respectively which mean, for the investigated period, $7 \%$ of the mean rainfall for the northern area and $18 \%$ for the South. This decreasing trend occurred particularly after 1950 since then the number of wet days $\left(N_{P}\right)$ has also decreased. The maximum annual temperature $\left(T_{y \max }\right)$ series show a slope of the regression line ranging between $0.4^{\circ} \mathrm{C} / 100$ years for $\mathrm{N}$ and $0.6^{\circ} \mathrm{C} / 100$ years for $\mathrm{S}$ while the minimum annual temperature $\left(T_{y \text { min }}\right)$ series show slope values between $0.3^{\circ} \mathrm{C} / 100$ years for $\mathrm{N}$ and $0.5^{\circ} \mathrm{C} / 100$ years for $\mathrm{S}$. According to Brunetti et al. [1], the most important contribution to this positive trend is due to roughly the last 20 years (before 1996) for $\mathrm{N}$ and to roughly the last 50 years for $\mathrm{S}$. In respect to extreme events, it has resulted an increase of rainfall intensity within both $\mathrm{N}$ and $\mathrm{S}$ areas [1], [2] and a tendency toward an increase in drought [3], [4], [5], [6].

Other investigations carried out in Italy [4], [7] showed a different behaviour of the same climatic series if a subdivision of the $\mathrm{N}$ and $\mathrm{S}$ areas into smaller subregions is taken into account.

For this reason, it seems necessary to investigate the climate change on a regional scale where different geographical factors (e.g. distance from the sea, elevation, aspect) are likely to influence the magnitude of these trends. Such investigation can be useful not only in terms of improving scientific knowledge but also to provide the Italian government with useful information in order to make the right choices in planning future activities.

Calabria and Sicily (Fig. 1) are two regions located in South Italy and are particularly prone to be investigated at local scale because of their geographic characteristics and local orographic features. In particular, Calabria $(\mathrm{Ca})$ is a narrow (with a width ranging from 30 to $95 \mathrm{~km}$ ) and long peninsula extending from North to South for about $250 \mathrm{~km}$; a mountain range (Apennine) runs in latitude and divides the region into two opposite areas: the Tyrrhenian and the Ionian zones. This mountain range is located almost perpendicularly to the direction of the dominant moisture-bearing winds and for this reason it causes a very strong variability in terms of rainfall and temperature patterns considering also the different altitudes and aspects [8]; that is why it is easy to find flat and semi-arid coastal areas ( $T_{y a}$ and $P_{y a}$ equal to $17.4^{\circ} \mathrm{C}$ and $683 \mathrm{~mm}$ respectively) as well as mountain zones with $T_{y a}$ equal to $9.1^{\circ} \mathrm{C}$ and $P_{y}$ equal to $1242 \mathrm{~mm}$ (the 
highest in the South). Locally, the annual rainfall $P_{y}$ ranges from $1107 \mathrm{~mm}$ over the Tyrrhenian area $(\mathrm{CaT})$ to $945 \mathrm{~mm}$ over the Ionian zone (CaI).
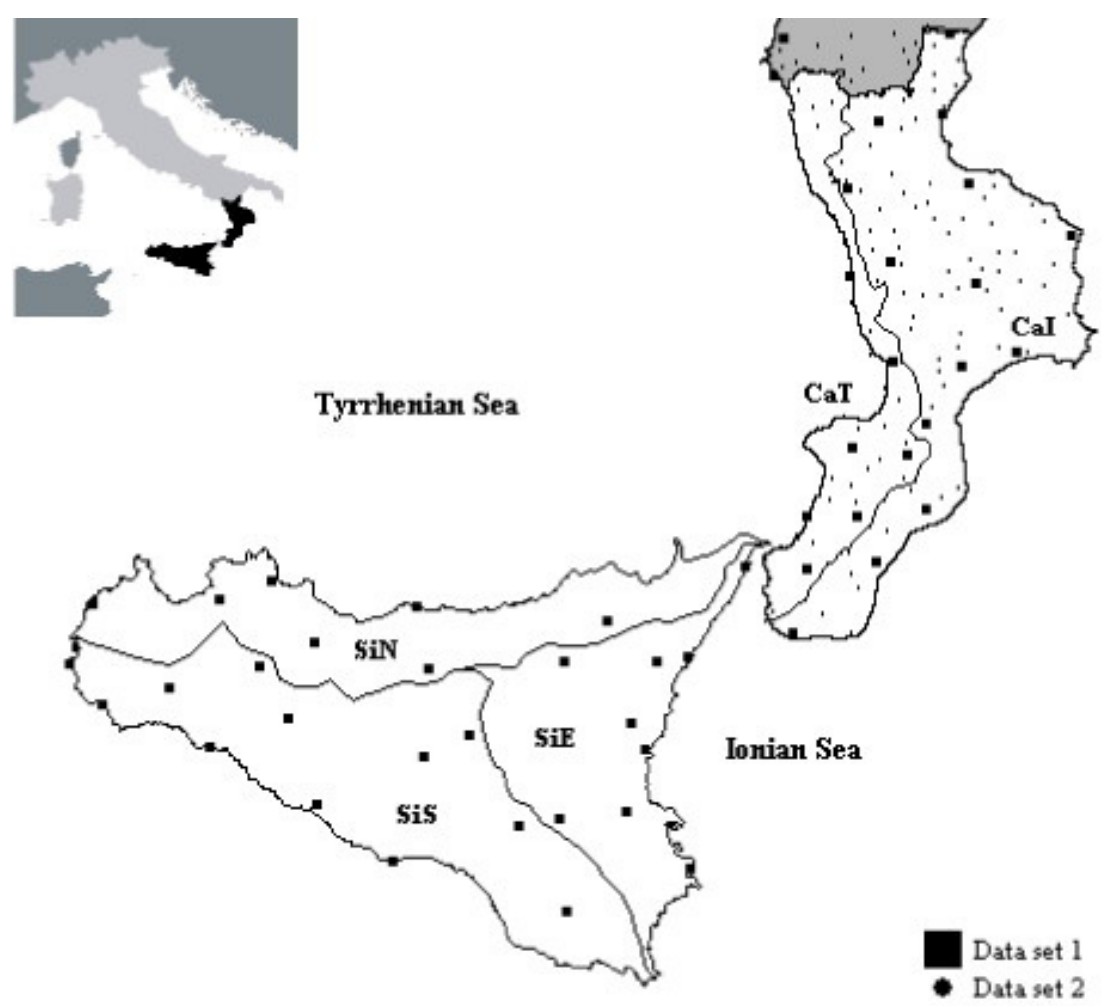

Figure 1: Location of investigated regions, sub-regions and weather stations. The two Calabrian sub-regions named Tyrrhenian and Ionian are marked with $\mathrm{CaT}$ and $\mathrm{CaI}$ respectively; $\mathrm{SiN}, \mathrm{SiS}$, and $\mathrm{SiE}$ represent North, South, and East zones of Sicily.

Sicily ( $\mathrm{Si}$ ) is the largest island of the Mediterranean Sea. According to traditional geographical distinctions for making sub-regional analysis, Sicily was divided into three homogeneous sub-regions (North, East, and South in Fig. 1). Each sub-region is separated from the others by mountain ranges and for this reason the rainfall pattern is different from area to area. Locally, the annual rainfall $P_{y}$ is $591 \mathrm{~mm}$ in the South area (SiS), $735 \mathrm{~mm}$ over the East area (SiE) and 717 within the North sub-region ( $\mathrm{SiN})$. Because of its particular geographic location in the centre of the Mediterranean Sea, Sicily was often investigated as a key region in order to explain the climate evolution within the Mediterranean basin [8]. 
To date, the studies carried out in this area are limited on a few stations ( 5 for temperatures and 11 for rainfalls - see Brunetti et al., [1], [2]) and for the reasons explained above it could be of interest to extend this investigation on a greater number of stations in order to give useful information on climate change in Mediterranean areas.

The study proposed here aims at analysing temperatures and precipitations over the two regions (Calabria and Sicily) for the period 1921-2000, using weather stations with high spatial resolution. The analysis also includes the use of bioclimatic indexes because in agro-forestry environments the consequences of climatic change depend on the interaction between temperatures (maximum, $T_{\max }$, minimum, $T_{\min }$, and mean, $\left.T_{a}\right)$ and rainfalls $\left(P_{m}\right)$, that can be summarised by appropriate indexes which account for aridity and plant water demand.

\section{Data and methods}

This paper investigates monthly values of temperature $\left(T_{\max }, T_{\min }\right.$, and $\left.T_{a}\right)$ and rainfall $\left(P_{m}\right)$ collected by the Italian Hydrographic Service (IHS) during the periods extending respectively from 1926 to 2000 and 1921 to 2000 . The IHS database concerning the two investigated regions includes about 120 temperature and 600 raingauge stations.

Even if a considerable number of stations was considered, many of these sites were neglected because long periods of malfunctioning.

The analysis was firstly carried out on a dataset including 53 temperature and raingauge stations ( 25 of which in $\mathrm{Ca}$ and 28 in $\mathrm{Si}$ ). These sites were selected considering the dataset continuity as well as geographic and altitude representativeness; datasets with more than $20 \%$ of lacks (with some exceptions) were also neglected.

An additional database including only rainfall series (monthly, seasonal and annual) and composed of 158 Calabrian stations was also used in the analysis in order to get more details about the spatial variability over the investigated regions. For this database an additional analysis involving the number of wet days, $N_{p}$, was carried out for the period 1951-2000. The analysed weather stations are located as in figure 1.

Although no specific tests were applied, we suppose that the series used here are homogeneous because they were collected using the same criterion that did not change during the analysed period; also, specific tests involving Sicilian data only, did not show particular anomalies due to malfunctioning [6].

The monthly values of $T_{\max }, T_{\min }, T_{a}$ and $P_{m}$ were also used to calculate the following indexes:

a) the monthly reference evapotranspiration, $E T_{0 m}$, estimated by Hargreaves formula [9] that, for sites where no direct radiation measurements are available, assumes the following form:

$$
E T_{0 m}=0.0023 R a\left(T_{a}+17.8\right) \sqrt{T_{\max }-T_{\min }} d
$$


where $R a\left(\mathrm{~mm} \mathrm{~d}^{-1}\right)$ is the extraterrestrial radiation, calculated on the basis of latitude and calendar day [10]; $d$ is the number of days of the month. The Hargreaves equation was chosen because it represents a good compromise between simplicity (because based on temperature data only) and goodness of results in many environments [10] including Sicily [11];

b) the aridity index, $A I$, calculated using the following equation:

$$
A I=\frac{P_{y}}{\sum_{j=1}^{12} E T_{0 m, j}}
$$

The monthly series of $T_{\max }, T_{\min }, T_{a}$ and $P_{m}$ were also analysed at sub-regional scale within the two Calabrian $(\mathrm{CaT}$ and $\mathrm{CaI})$ and the three Sicilian ( $\mathrm{SiN}, \mathrm{SiE}$ and $\mathrm{SiS}$ ) homogeneous sub-regions.

Seasonal and annual mean values of temperature and rainfall for each subregion were checked with the Mann-Kendall non-parametric test, as described in Hirsch et al. [12] to look for a trend. The slope of the trends was calculated by least-square linear fitting. An additional analysis involving the 10-years running averages was carried out with the aims to show the long period tendencies.

The indices $E T_{0 m}$ and $A I$ were analysed by splitting the study period into two sub-periods: from 1926 to 1962 and from 1963 to 2000. For each period, we calculated the slope of the regression lines and the percentage of stations for which the $t$-test [12] at the 0.05 level was significant.

\section{Results}

\subsection{Yearly and seasonal temperature and precipitation analysis}

The mean values $b$ of the calculated slopes of the regression lines for the investigated stations are listed in Table 1 together with the proportion of weather stations for which the Mann-Kendall test showed significant values (at the 0.05 level of significance).

The $T_{y a}$ values showed increasing trends in all zones and sub-zones, with $b$ values ranging from +0.1 to $+2.2{ }^{\circ} \mathrm{C} / 100$ years, with the only exception of $\mathrm{CaT}$ (where $b=-1.4^{\circ} \mathrm{C} / 100$ years). In general, the $b$ values calculated for $\mathrm{Si}$ were greater than those resulted in $\mathrm{Ca}$. The higher increments occurred during the winter season in $\mathrm{Si}$ and during the spring in $\mathrm{Ca}$ where $T_{y a}$ also showed a decreasing trend in autumn and, only for $\mathrm{CaT}$, in summer and winter.

The analysis carried out for $T_{\min }$ showed in most cases $b$ values greater than those related to $T_{\max }$. The $T_{\min }$ increase was similar in all seasons; conversely, the $T_{\max }$ increase was greater in autumn and in winter.

At seasonal scale, the analysis showed the highest $b$ values in $\mathrm{Si}$ and in particular for SiS.

The percent of weather stations for which the Mann-Kendall test (K, \%) showed significant values was always greater than $50 \%$ for the annual values of $T_{a}, T_{\max }$ and $T_{\min }$. At seasonal scale, the highest percentages occurred in $\mathrm{Si}$, with values greater than $80 \%$ particularly for $T_{m i n}$. 
Table 1: $\quad$ Mean values of linear regression coefficients $(b)$, and percent of stations with significant trend (Kendall's test, K, \%) for temperatures $(\mathrm{T})$ and rainfalls $(\mathrm{P})$ of Sicily $(\mathrm{Si})$ and Calabria $(\mathrm{Ca})$.

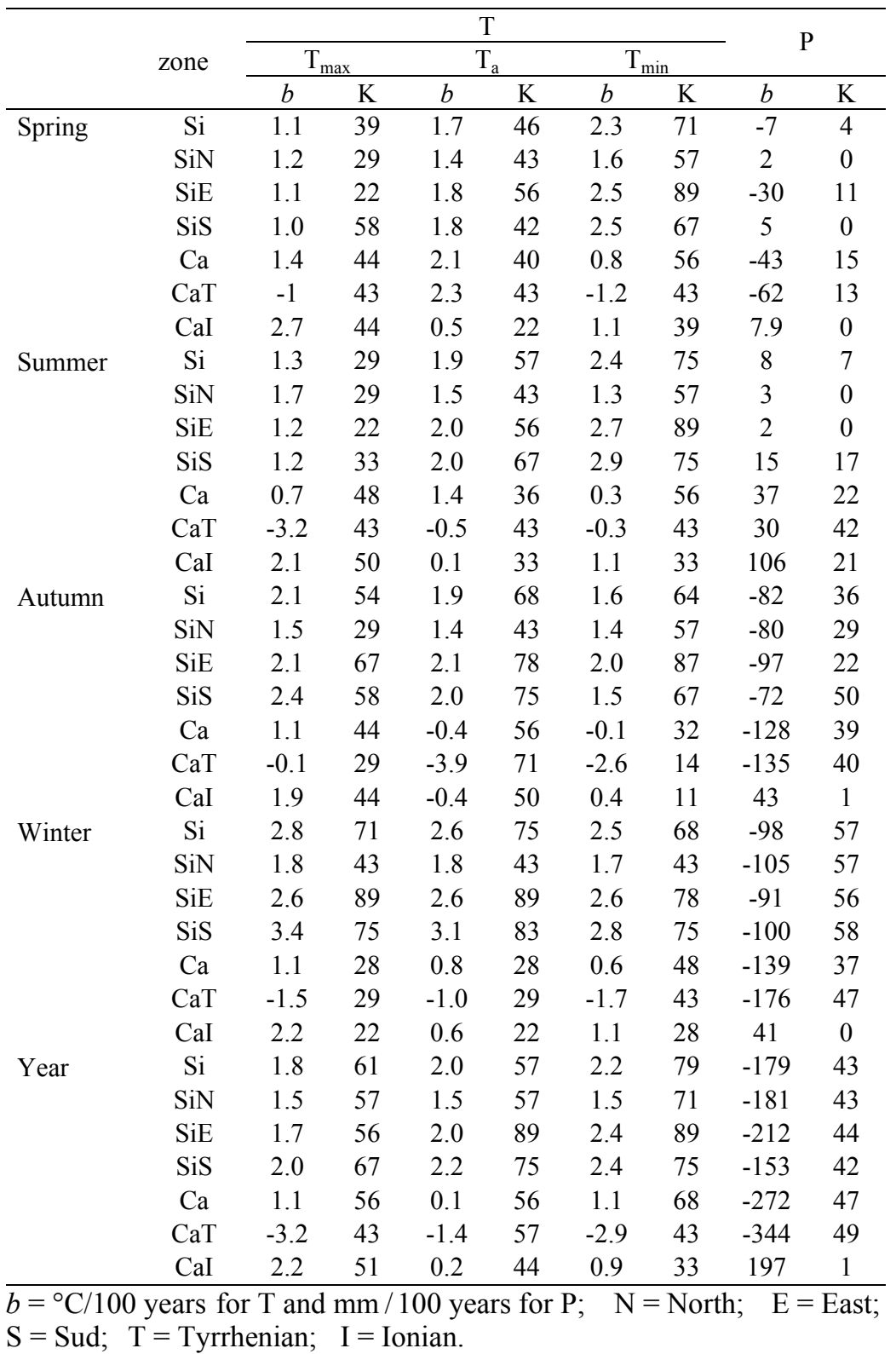

The annual values of rainfall showed decreasing trends in all zones and subzones, with $b$ values ranging from -153 to $-344 \mathrm{~mm} / 100$ years; the decrease was 
greater for $\mathrm{Ca}$ while it covered about $21 \%$ of the mean annual rainfall of the investigated period for both the regions. Where $b$ was positive $(\mathrm{CaI})$ the percent of stations with significant trends was very low (1\%) and can be neglected.

Negative trends occurred in autumn and winter, with $b$ values ranging from 72 to $-176 \mathrm{~mm} / 100$ years, with the only exception of CaI. During these seasons, although almost all the stations showed decreasing trends, these were significant, for more than $50 \%$ of the sites, only for winter rainfalls of $\mathrm{Si}$.

A greater variability occurred for spring rainfalls, while the summer ones showed positive values of $b$ (between 2 and $106 \mathrm{~mm} / 100$ years).

The rainfall decreasing trend seems to depend principally on the decrease of $N_{p}$ (number of wet days); in particular, for Ca, during the period 1951-1998, $N_{p}$ decreased of 32 days ( $b=67$ days/100 years); this decrease occurred especially during winter and spring.

Referring to long-period tendencies, the 10-years running averages showed complex and different behaviours from zone to zone and between the investigated climatic variables. $T_{y a}$ showed a strong increase since the $70 \mathrm{~s}$ (Fig. 2) for $\mathrm{Si}$; the trends are very similar from zone to zone. Conversely, the corresponding trends in $\mathrm{Ca}$, since the same period, seem to be decreasing (Fig. 2). In this case, if the $T_{a y}$ series are divided into two sub-periods of equal duration, it can be seen that in CaI, $b$ is increasing during the first sub-period (1926-1962) and almost equal to zero during the second one (1963-2000); in $\mathrm{CaT}, b$ was almost equal to zero during the first period and negative during the second one.

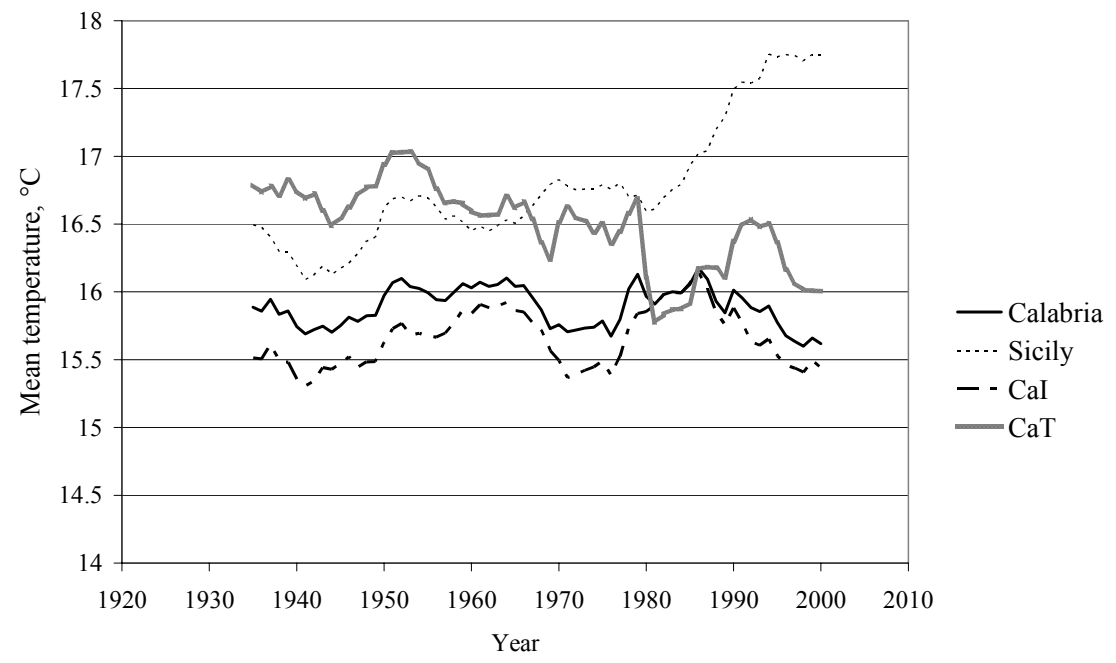

Figure 2: $\quad$ Ten-years running averages of annual mean temperature.

$P_{y}$ showed a decreasing trend, more clearly since the $50 \mathrm{~s}$, in both $\mathrm{Si}$ and $\mathrm{Ca}$. Even in this case, the 10-years running averages showed similar behaviours within the Sicilian sub-regions; conversely, in $\mathrm{Ca}$ the regional results seem to hide the increasing trend of CaI (Fig. 3). 


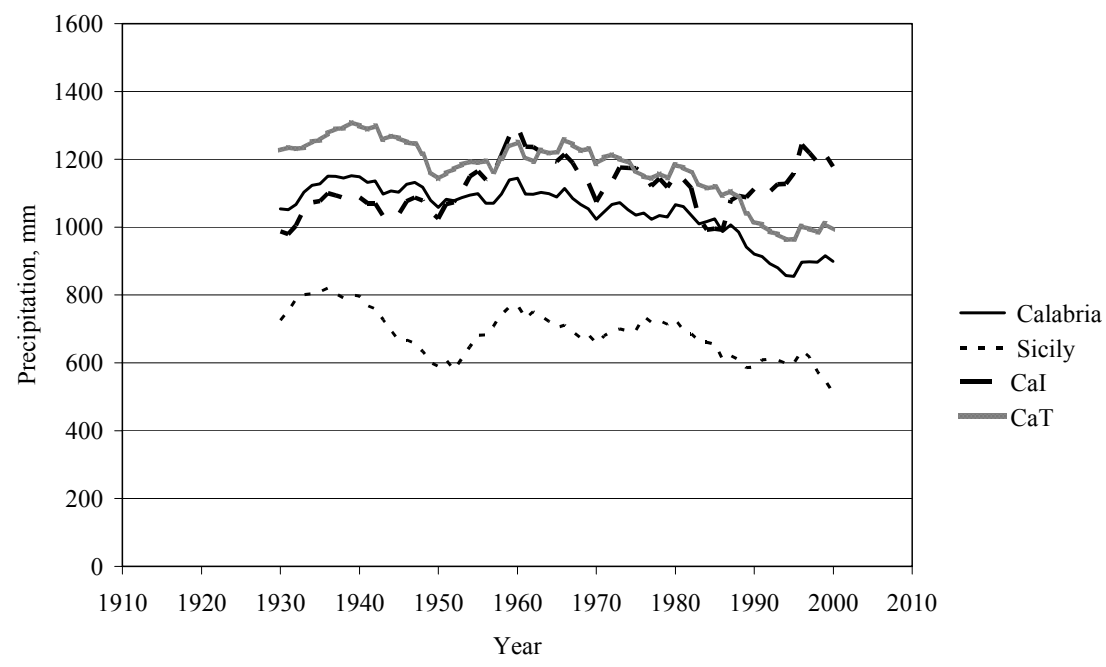

Figure 3: Ten-years running averages of annual precipitation.

Table 2: $\quad$ Mean linear regression coefficients $(b)$, and percent of stations with significant trend (t-test, \%) for Evapotranspiration $\left(E T_{0}\right)$ and Aridity index $(A I)$ for Sicily in the sub-periods 1926-62 and 19632000.

\begin{tabular}{rrcccccc}
\hline & \multicolumn{6}{c}{$E T_{0}$} & \multirow{2}{*}{$A I$} \\
\cline { 2 - 6 } $1926-62$ & $b$ & 29 & 82 & 21 & 22 & 154 & -0.2 \\
& $\mathrm{t}, \%$ & 25 & 25 & 25 & 25 & 25 & 18 \\
$1963-2000$ & $b$ & 58 & 35 & 7 & 40 & 150 & -0.3 \\
& $\mathrm{t}, \%$ & 50 & 25 & 39 & 46 & 46 & 14 \\
\hline
\end{tabular}

$b=\mathrm{mm} / 100$ year for $\mathrm{ET}_{0} ; \mathrm{mm}^{\prime} \mathrm{mm}^{-1} / 100$ years for $A I$.

\subsection{Bioclimatic indices analysis}

The annual values of $E T_{0}$ in Si showed $b$ values always positive and almost the same for the two investigated sub-periods during which its increase was about $5 \%$ of the $E T_{0}$ values calculated for the same sub-periods. At seasonal scale, the greatest rise occurred in summer, during the first sub-period (1926-1962) and in spring during the second one (1963-2000).

The proportion of weather stations that showed significant trends ( $t$-test at 0.05 level of significance) was greater during the second sub-period and this behaviour can be explained by the greater temperature increase occurred during the same period. The aridity index $A I$ showed a decrease in both the sub-periods, particularly during the second one (1963-2000), where it assumes a mean value equal to 0.62 (typical for sub-humid dry climate) that is less than the first period where its calculated mean value resulted equal to 0.70 (typical for sub-humid 
climate). The trends are significant (at the 0.05 level) for less than $20 \%$ of the considered weather stations.

\section{Conclusions}

The analysis carried out in this study which involved temperature and precipitation data covering a period of about 80 years, showed an increase of temperature (ranging from 0.1 and $2.2^{\circ} \mathrm{C} / 100$ years for the mean annual temperature) and a decrease of precipitation (ranging from 153 to $344 \mathrm{~mm} / 100$ years for the annual rainfall) over the two investigated regions (Calabria and Sicily) located in South Italy. The precipitation decrease can be explained by the decrease of the number of wet days $N_{P}$ according to other studies performed in different Italian regions. The calculated values of evapotranspiration $E T_{0}$, which accounted for mean $\left(T_{a}\right)$, maximum $\left(T_{\max }\right)$ and minimum $\left(T_{\min }\right)$ values of temperature, showed an increasing trend which was lower than that related to the temperature because $T_{\max }$ and $T_{\min }$ did not increase with the same magnitude.

The aridity conditions are not encouraging during the analysed period: the calculated Aridity Index $(A I)$ showed values which tend to decrease from a first sub-period (1926-1962) to a second one (1963-2000). This resulted in a climate change in Sicily from a sub-humid climate to a sub-humid dry climate.

Because of the geographic location and the particular orographic features of the two investigated regions which extend over $3^{\circ}$ of latitude, a strong difference in terms of climate change occurred. These main differences can be summarised as follows: a strong increase in temperature has occurred in Sicily since the 1970s, while in Calabria the same variable showed steady values or a light decrease; $T_{\max }$ and $T_{\min }$ values have clearly decreased during all the seasons over the Calabrian Jonian sub-region $\left(-3.2\right.$ e $-3.9{ }^{\circ} \mathrm{C} / 100$ years respectively for $T_{\max }$ and $T_{\min }$ ); rainfalls have increased over the Calabrian Ionian sub-region (197 $\mathrm{mm} / 100$ years for $P_{y}$ ).

The overall results showed the importance of the climate change analyses at a regional scale and provide the Italian authorities with useful information to begin to assess the impacts of such climate changes on human activities.

\section{References}

[1] Brunetti, M., Buffoni, L. \& Mangianti, F., Temperature, precipitation and extreme events during the last century in Italy, Global and Planetary Change, 40, pp. 141-149, 2004.

[2] Brunetti, M., Buffoni, L., Maugeri \& M, Nanni, T., Trend of minimum and maximum daily temperatures in Italy from 1865 to 1996, Theor. Appl. Climatol., 20, pp. 1017-1031, 2000.

[3] Capra, A., Indelicato, S., Li Destri Nicosia, O. \& Scicolone, B., Evaluation de la sécheresse d'aprés les données de précipitation. Une application au Sud d'Italie, Proc. of the $16^{\text {th }}$ European Regional Conf., ICID, Budapest, Hungary, June, pp. 41-51, 1992. 
[4] Capra, A., Li Destri Nicosia, O. \& Scicolone B., Application of fuzzy sets to drought classification, Proc. of the $2^{\text {nd }}$ Int. Conf. On Advances in Water Resources Technology and Management, Eds. G. Tsakiris \& M.A. Santos, Balkema, Rotterdam, pp. 479-483, 1994.

[5] Piccarreta, M., Capolongo, D. \& Boenzi, F., Trend analysis of precipitation and drought in Basilicata from 1923 to 2000 within a southern Italy context, Int. Journal of Climatology, 24, pp. 907-922, 2002.

[6] Rossi, G. \& Cancelliere, A., Problemi e prospettive del monitoraggio e delle mitigazione della siccità, Editoriale Bios, Cosenza, Quaderni di Idrotecnica, pp. 9-44, 2002 (in Italian).

[7] Capra A., Malara, S.L. \& Scicolone, B., (2004), Analisi delle temperature e delle piogge mensili in Calabria nell'ultimo cinquantennio, Economia Montana-Linea Ecologica, 3, pp. 31-36, 2004 (in Italian).

[8] ENEA, Cambiamenti climatici e rischi di siccità e desertificazione in area mediterranea ed in Sicilia, Progetto speciale clima globale, Roma, Italy, giugno, 2002 (in Italian).

[9] Hargreaves, G.H. \& Samani, Z.A., Reference crop evapotranspiration from temperature. Transactions of the ASAE, 1(2), 96-99, 1985.

[10] FAO, Crop evapotranspiration. Guidelines for computing crop water requirements, FAO Irrigation and drainage Paper, 56, 1998.

[11] Di Stefano, C. \& Ferro, V., Estimation of Evapotranspiration by Hargreaves Formula and Remotely Sensed Data in Semi-arid Mediterranean Areas, J. Agric. Engng Res., 68, 189-199, 1997.

[12] Hirsch, R.M., Helsel, D.R., Cohm, T.A. \& Gilroy, E.J., Statistical analysis of hydrological data, Handbook of Hydrology, Ed. Maidment, D.R., McGraw-Hill, pp. 17.1-17.55, 1993. 